\title{
Introduction: Discourse, grammar and intersubjectivity
}

\section{Marja Etelämäki}

\begin{abstract}
This special issue includes a collection of papers on language and intersubjctivity. There are two paradigms in linguistic approaches to intersubjectivity; cognitive linguistics and interactional linguistics, but these two paradigms hardly ever meet. This is due to the fact that these paradigms have opposing views on cognition and mental events. However, both these paradigms draw from phenomenology: whereas cognitive linguistic approaches to intersubjectivity have their basis on Husserl's philosophy, interactional linguistics is influenced by ethnomethodological conversation analysis and the philosophy of Schutz. Despite the apparent differences between these approaches, there are convergences, too. Moreover, both approaches are needed for a full account of language and human intersubjectivity.
\end{abstract}

Keywords cognitive linguistics, conversation analysis, interactional linguistics, intersubjectivity, phenomenology

Marja Etelämäki, Department of Linguistics and Scandinavian Studies, University of Oslo, P.O. Box 1102, Blindern, 0317 Oslo, Norway.m.i.etelamaki@iln.uio.no

Human mind, language, and action are nowadays understood and studied as thoroughly social and intersubjective phenomena in many fields of research; simultaneously, human sociality and intersubjectivity per se have become topics for multidisciplinary studies. At present, studies concerning human intersubjectivity have at least three foci. One approach focusses on intersubjectivity as a property of the human mind, drawing on research in philosophy, psychology, and cognitive and neuroscientific studies (e.g. Bråten 2006, Hari \& Kujala 2009, Rochat, PassosFerreira \& Salem 2009, Zahavi \& Rochat 2015). Another focus is on language and intersubjectivity as cognitive phenomena (e.g. Verhagen 2005, 2008). The third line of research has its roots in sociology, where intersubjectivity is understood as an achievement of organized social interaction (e.g. Heritage 1984, Schegloff 1992, Sidnell 2014). Within this approach, the focus is on intersubjectivity as situated in the social world rather than the human mind. Drawing on the methodology of conversation analysis, this approach is radically empirical, emphasizing the importance of recorded data from authentic interactions.

Regardless of a shared understanding of humans as thoroughly social beings, these three lines of research do not easily meet. While psychological studies have, 
to a large extent, neglected the role of language in the constitution of human intersubjectivity, ${ }^{1}$ cognitive linguistic studies of language and intersubjectivity are either purely theoretical or focus on language as a means for sharing experience at the cognitive level, neglecting the affective and action-oriented levels of human interaction. On the other hand, interactionally oriented empirical studies on language and intersubjectivity mainly neglect - some even reject - the cognitive dimension. The result is that there is only a handful of empirical studies that approach grammar as a socio-cognitive, profoundly interactional and affect-oriented phenomenon, and hardly any of these use authentic interaction as data.

This special issue wishes to bring language into the fore in the studies in intersubjectivity. Moreover, it aims at initiating a dialogue between interactionally and cognitively oriented studies on language and intersubjectivity. Interestingly, both of these lines of linguistic research have their roots in phenomenology, whose primary focus is on the structures of conscious experience. They draw, however, from differing lines of phenomenological studies. Whereas the approach to intersubjectivity in cognitive linguistics has its roots in Edmund Husserl's phenomenology (see Zahavi 2003) and, in addition, on Maurice Merleau-Ponty's phenomenology of the body (e.g. Merleau-Ponty [1945] 1962), conversation analysis and interactional linguistics have their roots in Alfred Schutz's phenomenology of the social world (Schutz 1967; also Schutz \& Luckmann 1973). This is due to the originally different foci of these two approaches.

Cognitive linguists are, basically, interested in the relation of language, mind, and the world. In particular, they study meaning as residing in conceptualization (Langacker 2008), and as grounded in bodily experiences (e.g. Lakoff \& Johnson 1980, 1999; Zlatev 2008, 2013; Jääskeläinen 2014). The nature of conceptualization is, however, a topic of debate. Langacker (e.g. 1987, 2008) claims that conceptualization can be approached from the standpoint of cognitive processing; the papers in this volume (in particular, Zlatev \& Blomberg and Möttönen), however, take the phenomenological standpoint. One of the main arguments for the latter is that language is by default a social and normative phenomenon. If it were reduced to mere cognitive processing of an individual brain, the intersubjective validation that is necessary for any meaningful communicative act would be lost (see also Möttönen 2016).

In a similar vein, there is a debate on the relation of pre-linguistic bodily experiences to linguistic meaning and, in particular, on the relation of image-schemas to conceptual metaphors (see Zlatev 2010, Jääskeläinen 2013, and their papers in this volume). If linguistic meanings were directly reducible to pre-linguistic bodily experiences, how could we explain their conventionality, and differences between metaphors across languages? Moreover, if linguistic meanings were directly reducible to individual bodily experiences, how could we maintain the crucial separation of Self from the Other, which is a prerequisite for intersubjectivity (Zahavi 
2003:114)? These problems can, however, be overcome, if conventional linguistic meaning is understood as sedimented upon pre-linguistic, embodied intersubjectivity (intercorporeality, Merleau-Ponty [1960] 1964:168), ${ }^{2}$ but not reducible to it (Zlatev \& Blomberg, this volume).

Whereas debates on intersubjectivity between different approaches to cognitive linguistics exist, there is practically a silence between cognitive linguistics and interactional approaches to language (see, however, Etelämäki, Herlin, Jaakola \& Visapää 2009, Etelämäki \& Visapää 2014, Zima \& Brône 2015). This has to do with the fact that the two paradigms have seemingly opposing views on cognitive notions such as intentionality: whereas human cognition, naturally, has an important role in cognitive linguistics, conversation analysts and conversation-analysis-influenced interactional linguists mostly take an agnostic stance towards cognition in the sense of cognitive events (Heritage 1984:54-61). The reason for this is that conversation analysis has its roots in the phenomenology of Schutz ${ }^{3}$ who, instead of analyzing the structures of experience that provide for intersubjectivity, understood intersubjectivity as a practical problem in everyday encounters. We live in an intersubjective and a cultural world where, in everyday interactions, we routinely rely on the idealization of the interchangeability of the standpoints, and on the idealization of the congruency of the system of relevance:

The differences in perspectives originating in our unique biographical situations are irrelevant for the purpose at hand of either of us and that he and I, that "We" assume that both of us have selected and interpreted the actually or potentially common objects and their features in an identical manner or at least an "empirically identical" manner, i.e., one sufficient for all practical purposes. (Schutz 1953:8)

In other words, as long as our common understanding of the situation seems to be sufficient enough for the encounter to go on, we rely on the belief that we are in an intersubjective understanding without problematizing what it is that actually happens in the other's mind. This has brought the organization of a social situation as a research object per se (Goffman 1964, Garfinkel 1967) along with the practices that members of a culture use in order to make sense of each other's actions and to engage in joint-projects (see, e.g. Sacks, Schegloff \& Jefferson 1974, Sacks 1992, Schegloff 2007, Sidnell \& Stivers 2014).

It needs to be noted, however, that contrary to a common misconception, conversation analysts do not deny the existence of intentions. They only avoid making reference to individual intentions or other mental states in the analyses, unless these are displayed in the data. The participants of an interaction do not, themselves, have a direct access to each other's mental states; they only have access to the displays of intentions, emotions and the like. ${ }^{4}$ Since the conversation-analytic endeavor is to disclose the ways in which the participants of an interaction make sense of each 
other's actions in a sequence of interaction, the method would lose its research object if turns-at-talk were explained by reference to invisible and inaccessible mental states (to the participants as well as to the analyst). Moreover, the product of an interaction is always something else than a total sum of the consciously intentional acts of the participants, thus interaction is not reducible to individual intentions of the participants.

Despite this apparent difference between cognitive and interactional linguistic approaches to intersubjectivity, they both share the understanding that linguistic intersubjectivity is based on normativity. There is normativity in linguistic structure as well as in language use (Itkonen 1997, 2008), and there is normativity in everyday practices in social interaction (Heritage 1984:115-120) to the extent that they become conventionalized in linguistic structure (e.g. Couper-Kuhlen \& Selting 2001, Hakulinen \& Selting 2005, Thompson, Fox \& Couper-Kuhlen 2015). Moreover, both paradigms agree upon the fact that life-world in which language is included, which is an important notion in both Husserl's and Schutz's philosophy, is the intersubjectively validated social reality in which we live in. However, whereas cognitive linguists focus upon the more stable and conventionalized aspects of language and linguistic structure, conversation analysts and interactional linguists focus upon the means by which social interaction and linguistic structure are produced and intersubjectively validated in situ.

The papers in this special issue are organized along a continuum which begins with empirical and interactional analyses of language, interaction, and empathy, continues to empirical analyses of mimetic schemas and the sedimentation of linguistic meaning, and ends with a meta-theoretical discussion of conventionalized intentionality. The papers can be, roughly, divided under three themes: (i) the construal of intersubjectivity in interaction, (ii) the sedimentation of linguistic meaning upon embodied intersubjectivity, and (iii) the linguistic architecture of intersubjectivity.

The first two papers approach intersubjectivity primarily as a social phenomenon that comes into being in-between the participants of an interaction, and analyze the linguistic means for creating and maintaining intersubjectivity in interaction. The paper by PER LINELL \& JAN LINDSTRÖM discusses a particular Swedish construction, the $x$ - $\stackrel{a}{-}-x$ construction (e.g. flytta a flytta 'move and move'). This construction is used in responsive turns; it picks up an element $(x)$ from the previous speaker's turn, and the turn in which it occurs suggests a clarification for the situated meaning of $x$. By focusing on this particular construction, Linell \& Lindström show the way in which the constant responsiveness of each turn in a conversational sequence takes part in the weave of intersubjective understanding. In this paper, intersubjectivity in interaction is understood as partial and dynamic (see also Linell 2009); the mutual understanding between the participants of an interaction needs to be merely sufficient enough 'for all practical purposes' (e.g. Schutz 1953:8). There is, however, yet another aspect of the 
$x$ - $\stackrel{a}{-}-x$ construction, namely that its pragmatic meaning conveys that there are multiple understandings of $x$. The construction is, thus, itself a manifestation of interactional positions that are conventionalized in grammar (see Möttönen, this volume).

Whereas Linell \& Lindström discuss the dynamically evolving intersubjective understanding in interaction, ILONA HERLIN \& LAURA VISAPÄ̈̈ trace the roots of intersubjectivity by analyzing empathy in everyday interaction. By using one troubles-telling sequence as an example, they show the ways in which different dimensions of empathy are evoked and expressed in different phases of troublestelling. They approach empathy as a dynamic process that includes three dimensions: emotional contagion, a cognitive dimension and an affective dimension. By combining theoretical insight from cognitive grammar with methodological insight from conversation analysis, Herlin \& Visapää analyze the linguistic means for construing the degree of empathetic sharing in interaction. Moreover, they suggest that linguistic analysis may give concrete tools for analyzing and understanding how empathy takes place in real-life encounters.

The next two papers deal with embodied intersubjectivity and mimetic schemas (see Zlatev 2008). ANNI JÄÄSKELÄINEN examines the use of two Finnish imitatives (ideophones that depict sound), humps and naps, in written texts. These two words are used primarily for portraying sounds: humps, portraying the sound of relatively soft falling, and naps ('snap'), the sound of a sudden change, e.g. snapping. Jääskeläinen argues that the basic bodily actions that are the pre-linguistic basis for mimetic schemas are most often accompanied by sounds, and hearing is therefore a sourcesense for mimetic schemas alongside vision and proprioception. She shows that these two words, humps in particular, are semantically synesthetic; together with sound, humps may also depict movement and other sensory impressions. Moreover, these two imitatives have more abstract, metaphoric usages for depicting emotions, particular kinds of temporal movement (slow or sudden), etc. Jääskeläinen suggests that the literal as well as the metaphoric uses of these words is based on intersubjectively shared mimetic schemas that render the sharing of profoundly individual experiences such as feelings.

JORDAN ZLATEV \& JOHAN BLOMBERG focus on the relation between embodied intersubjectivity (intercorporeality) and linguistic meaning. The paper is a phenomenological as well as an empirical investigation on linguistic meaning, drawing on the philosophy of Husserl and Merlau-Ponty. Zlatev \& Blomberg argue that linguistic meaning is intrinsically layered in human experience. It is sedimented upon but not reducible to pre-linguistic, experiential structures of embodied intersubjectivity. Whereas linguistic meaning is more abstract and stable than pre-linguistic, experiental structures of embodied intersubjectivity, the latter are more experientially rich, and latent but may be reactivated in specific contexts. Zlatev \& Blomberg demonstrate this, first by reviewing evidence from ontogenetic semiotic development within the framework of the Mimesis Hierarchy model (see 
Zlatev 2013) and then, by reviewing studies of non-actual motion (e.g. The road goes through the forest) in several languages. Their analysis shows that body and sociality are fused from the beginning and, by showing that pre-linguistic bodily experiences are not purely subjective, bridges the gap between mimetic schemas and normative, linguistic meaning.

The last paper is the most theoretical one: Like Zlatev \& Blomberg, TAPANI MÖTTÖNEN draws on the philosophy of Husserl in his meta-theoretical discussion on linguistic construal in cognitive grammar (see e.g. Langacker 1987, 2008). Möttönen proposes that linguistic meaning, i.e. conceptualization, is best understood as acquired in multiple intersubjectively validated usage events and that it cannot be reduced to cognitive processing (see Langacker 2008:30). He argues that since linguistic meaning is social and, more importantly, normative (see Itkonen 1997, 2008) by nature, and that since linguistic signs are used to convey meaning about extralinguistic, extramental reality, linguistic meaning cannot be grounded in individual cognitive phenomena. The key notions in Möttönen's paper are nonobjective meaning, intersubjectivity, and intentionality. By non-objective meaning Möttönen refers to the fact that linguistic signs necessarily express an in-built perspective; any linguistically accomplished reference to an object is always a construal of that object, and any object that can be referred to linguistically has multiple linguistic construals. This means that linguistic meaning is intentionality that is conventionalized in linguistic structure.

Despite the seemingly different starting points of the papers collected in this issue, they share common themes. The papers by Linell \& Lindström, Herlin \& Visapää, and Möttönen all promote an understanding that linguistic structure is in itself a manifestation of intersubjectivity, because any linguistic object is necessarily perspectival and, moreover, any utterance necessarily positions the participants of an interaction in relation to each other (see also Verhagen 2005, 2008; Etelämäki \& Visapää 2014). Linguistic structure, thus, conveys the existence of the multitude of other subjects. The papers by Herlin \& Visapää, Jääskeläinen, and Zlatev \& Blomberg, all deal with embodied intersubjectivity, and its relation to linguistic meaning. Whereas Herlin \& Visapää show how language and the body function for evoking and displaying dimensions of empathy in interaction, Jääskeläinen, as well as Zlatev $\&$ Blomberg, discuss the intersubjective basis for bodily experiences. They show how the embodied intersubjectivity can become conventionalized in linguistic structure for expressing more abstract meanings, these conventionalized expressions yet maintaining the possibility to evoke the experientially more rich content of their origins.

Finally, I would like highlight an apparent convergence of the radically empirical conversation analysis in the last, most theoretical and most cognitive paper of this issue (Möttönen). It emphasizes the social and normative nature of language, and the necessity of intersubjective validation of linguistic meaning. The paper follows Itkonen (1997:55) in describing the structure of common knowledge: 
1. A knows $\mathrm{x}$,

2. A knows that B knows $\mathrm{x}$,

3. A knows that B knows that A knows $\mathrm{x}$.

In conversation, intersubjectivity is provided by double-contextuality (Heritage 1984:242) and its interpretative corollary (Heritage 1984:254-260): every turn-attalk provides an interpretation of the previous turn, and is interpreted with respect to is as follows:

1. A does $\mathrm{x}$,

2. B's turn provides an interpretation of A's action, and is interpreted with respect to it,

3. A's turn accepts B's interpretation by explicitly acknowledging it or merely continuing the conversation.

This means that if A does not initiate repair in the third turn, B's interpretation of A's initial action remains valid - regardless of A's original intention (see also Schegloff 1992). In other words, as a method, conversation analysis focuses upon the intersubjective validation of shared knowledge in situ, and in this way, we can see where the thinking behind Möttönen's paper meets the ethnomethodological thinking originating in Schutz's philosophy. The cognitive approaches to language and intersubjectivity often deal with the more conventionalized aspects of language, and the interactional approaches examine the situated practices of intersubjectivity. Yet, the former presuppose intersubjective validation of linguistic conventions, and the latter also rely on normativity with respect to interactional practices. In order to understand human intersubjectivity with respect to language as a whole, we need both these approaches; and hopefully these approaches will find one another.

\section{ACKNOWLEDGEMENTS}

I would like to thank my co-editors Ilona Herlin and Laura Visapää for their encouraging support and comments during the writing of this introduction. My work on writing this introduction as well as editing this special issue has been supported by the Kone Foundation and the Finnish Centre of Excellence in Intersubjectivity in Interaction (intersubjectivity.fi).

\section{NOTES}

1. There are several studies that concern language and intersubjectivity in ontogeny, but hardly any that concern language and intersubjecitivity between adults with fully developed languages skills. 
2. The philosophy of Merleau-Ponty and the notion of intercorporeality are central in current, multimodal approaches to interaction (see e.g. Streeck 2009, Haddington, Mondada \& Nevile 2013). This point is not taken up in the current special issue that focuses on language, but is well worth noting when building bridges across paradigms.

3. Particularly influential has been Harold Garfinkel's interpretation of Schutz, see Heritage 1984.

4. There are places in interaction where intentions can, rightfully, argue to be surfaced, e.g. the so-called third and fourth position repairs (see Schegloff 1992), and 'second tries' after a turn-at-talk has been sequentially deleted.

\section{REFERENCES}

Bråten, Stein (ed.). 2006. Intersubjective Communication and Emotion in Early Ontogeny. Cambridge: Cambridge University Press.

Couper-Kuhlen, Elizabeth \& Margret Selting (eds.). 2001. Studies in Interactional Linguistics. Amsterdam: John Benjamins.

Etelämäki, Marja, Ilona Herlin, Minna Jaakola \& Laura Visapää. 2009. Kielioppi käsitteistyksenä ja toimintana. Kognitiivista kielioppia ja keskustelunanalyysia yhdistämässä [Grammar as conceptualization and as action]. Virittäjä 113, 162-187.

Etelämäki, Marja \& Laura Visapää. 2014. Why blend cognitive grammar with conversation analysis? In Ritva Laury, Marja Etelämäki \& Elizabeth Couper-Kuhlen (eds.), Pragmatics. Approaches to Grammar for Interactional Linguistics 24(3), 477-506.

Garfinkel, Harold. 1967. Studies in Ethnomethodology. Cambridge: Polity Press.

Goffman, Ervin. 1964. The neglected situation. American Anthropologist 66 (6, pt.2), 133-136.

Haddington, Pentti, Lorenza Mondada \& Maurice Nevile (eds). 2013. Interaction and Mobility: Language and the Body in Motion. Berlin \& Boston, MA: Walter de Gruyter.

Hakulinen, Auli \& Margret Selting (eds.). 2005. Syntax and lexis in conversation. Amsterdam: John Benjamins.

Hari, Riitta \& Miiamaria V. Kujala. 2009. Brain basis of social interaction: From concepts to brain imaging. Physiological Reviews 89, 453-479.

Heritage, John. 1984. Garfinkel and Ethnomethodology. Cambridge: Polity Press. Itkonen, Esa. 1997. The social ontology of linguistic meaning. In Timo Haukioja, Marja-Liisa Helasvuo \& Matti Miestamo (eds.), SKY Yearbook, 49-80. Helsinki: The Linguistic Association of Finland.

Itkonen, Esa. 2008. The central role of normativity in language and linguistics. In Zlatev et al. (eds.), 279-305.

Jääskeläinen, Anni. 2013. Todisteena äänen kuva. Suomen kielen imitatiivikonstruktiot [Imitations of sounds as evidence: The constructions of imitatives in the Finnish language]. Ph.D. dissertation. University of Helsinki.

Lakoff, George \& Mark Johnson. 1980. Metaphors we Live by. Chicago, IL: The University of Chicago Press.

Lakoff, George \& Mark Johnson. 1999. Philosophy in the Flesh: The Embodied Mind and its Challenge to Western Thought. Chicago, IL: The University of Chicago Press.

Langacker, Ronald W. 1987. Foundations of Cognitive Grammar: Theoretical Prerequisites. Stanford, CA: Stanford University Press. 
Langacker, Ronald W. 2008. Cognitive Grammar: A Basic Introduction. Oxford: Oxford University Press.

Linell, Per. 2009. Rethinking Language, Mind and World Dialogically: Interactional and Contextual Theories of Human Sense-making. Charlotte, NC: Information Age Publishing.

Merleau-Ponty, Maurice. [1945]1962. Phenomenology of Perception. Transl. by Colin Smith. London: Routledge.

Merleau-Ponty, Maurice. [1960]1964. The philosopher and his shadow. In Signs, transl. by Richard C. McCleary, 159-181. Evanston, IL: Northwestern University Press.

Möttönen, Tappani. 2016. Construal in Expression: Intersubjective Approach to Cognitive Grammar. Ph.D. dissertation. University of Helsinki.

Rochat, Philippe, Cláudia Passos-Ferreira \& Pedro Salem. 2009. Three levels of ntersubjectivity in early development. In Antonella Carassa, Francesca Morganti \& Giuseppe Riva (eds.), Enacting Intersubjectivity: Paving the Way for a Dialogue between Cognitive Science, Social Cognition and Neuroscience, 173-190. Lugano: Università della Svizzera Italiana.

Sacks, Harvey. 1992. Lecture on Conversation, vols. 1 \& 2. Oxford: Blakwell.

Sacks, Harvey, Emanuel A. Schegloff \& Gail Jefferson 1974. A simplest systematics for the organization of turn-taking for conversation. Language 50, 696-735.

Schegloff, Emanuel A. 1992. Repair after next turn: The last structurally provided defense of intersubjectivity in conversation. American Journal of Sociology 97(5), 12951345.

Schegloff, Emanuel A. 2007. Sequence Organization in Conversation: A Primer in Conversation Analysis. Cambridge: Cambridge University Press.

Schutz, Alfred. 1953. Common-sense and scientific interpretation of human action. Philosophy and Phenomenological Research 14(1), 1-38.

Schutz, Alfred. 1967. Collected Papers I: The Problem of Social Reality. The Hague: Martinus Nijhoff.

Schutz, Alfred \& Thomas Luckmann.1973. The Structures of the Life-World, vol.I. Transl. by Richard M. Zaner \& H. Tristram Engelhardt, Jr. Evanston, IL: Northwestern University Press.

Sidnell, Jack. 2014. The architecture of intersubjectivity revisited. In Nick J. Enfield, Paul Kockelman \& Jack Sidnell (eds.), The Cambridge Handbook of Linguistic Anthropology, 357-390. Cambrige: Cambride University Press.

Sidnell, Jack \& Tanya Stivers (eds.). 2013. The Handbook of Conversation Analysis. Chichester: Wiley-Blackwell.

Streeck, Jürgen. 2009. Gesturecraft: The Manu-facture of Meaning. Amsterdam: John Benjamins.

Thompson, Sandra A., Barbara A. Fox \& Elizabeth Couper-Kuhlen (eds.). 2015. Grammar in Everyday Talk: Building Responsive Actions. Cambridge: Cambridge University Press.

Verhagen, Arie. 2005. Constructions of Intersubjectivity: Discourse, Syntax, and Cognition. Oxford: Oxford University Press.

Verhagen, Arie. 2008. Intersubjectivity and the architecture of language system. In Zlatev et al. (eds.), 307-331.

Zahavi, Dan. 2003. Husserl's Phenomenology. Stanford, CA: Stanford University Press.

Zahavi, Dan \& Philippe Rochat. 2015. Empathy $\neq$; sharing: Perspectives from phenomenology and developmental psychology. Consciousness and Cognition 36, 543-553. 
Zima, Elisabeth \& Geert Brône (eds.). 2015. Cognitive Linguistics and interactional discourse: Time to enter into dialogue. In Elisabeth Zima \& Geert Brône (eds.), Cognitive Linguistics and Interactional Discourse: Special issue of Language and Cognition 7(4), 485-498.

Zlatev, Jordan. 2008. The co-evolution of intersubjectivity and bodily mimesis. In Zlatev et al. (eds), 215-244.

Zlatev, Jordan. 2010. Phenomenology and cognitive linguistics. In Shaun Gallagher \& Daniel Schmicking (eds.), Handbook of Phenomenology and Cognitive Science, 415-443. Berlin: Springer.

Zlatev, Jordan. 2013. The mimesis hierarchy of semiotic development: Five stages of intersubjectivity in children. Public Journal of Semiotics 4, 47-70.

Zlatev, Jordan, Timothy P. Racine, Chris Sinha \& Esa Itkonen (eds.). 2008. The Shared Mind: Perspectives on Intersubjectivity. Philadelphia, PA: John Benjamins. 


\section{TRANSCRIPTION SYMBOLS AND GLOSSING ABBREVIATIONS USED IN THIS SPECIAL ISSUE}

\section{Transcription symbols}

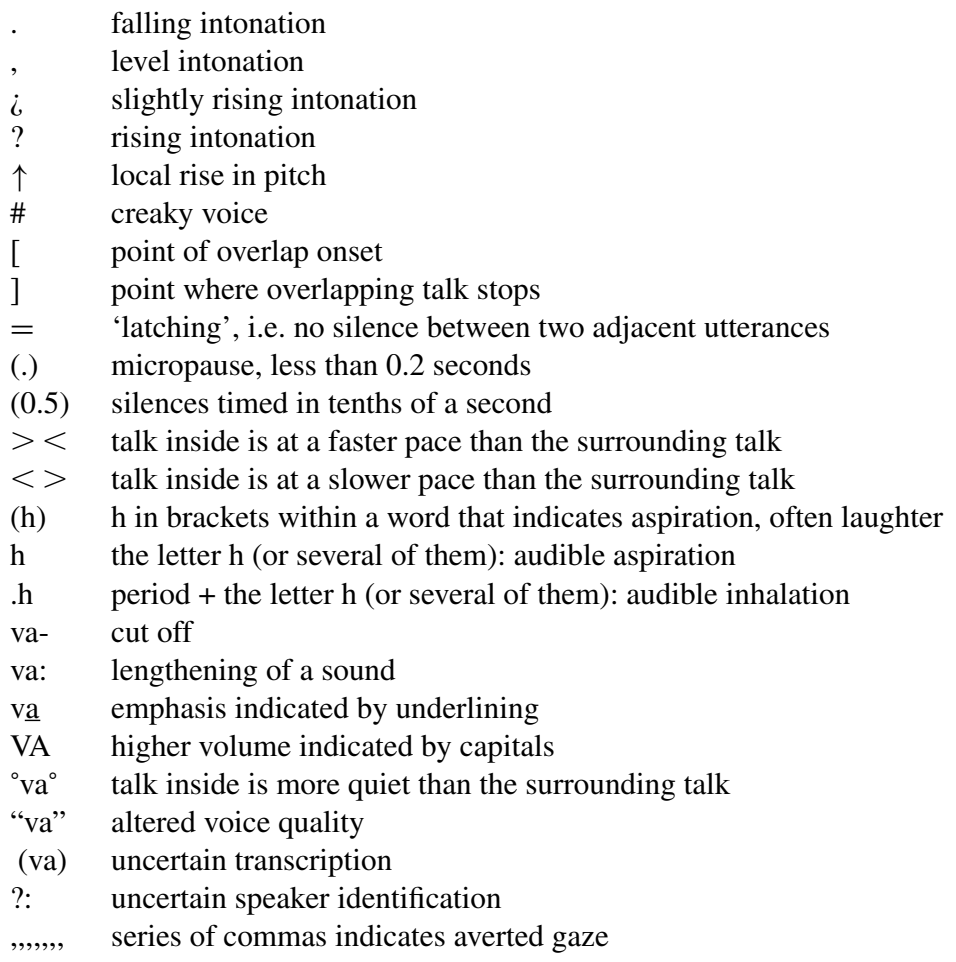

\section{Glossing abbreviations}

1SG first person singular

3SG third person singular

ABL ablative

ADE adessive

ADV adverbial

CLI clitic

COMP complementizer

COND conditional

CONJ conjunction

COP copula

DEF definite

DEM demonstrative pronoun

DET determiner

ESS essive 


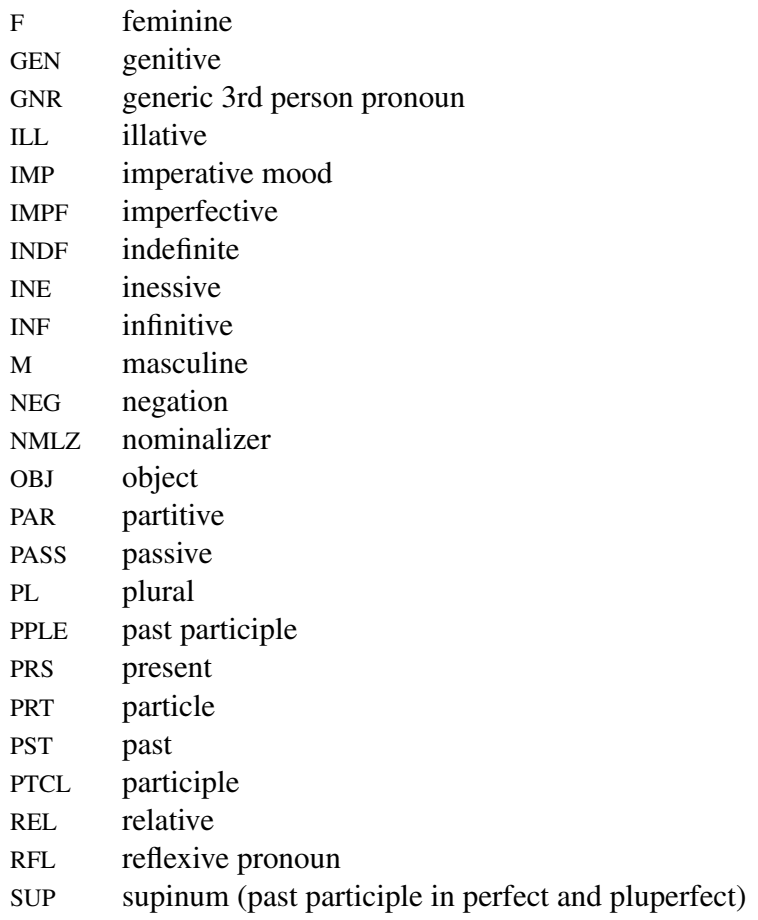

Infinitive and present tense forms are not glossed when the context and translation indicate these forms clearly sufficiently. 